\title{
Physiological and Biochemical Zoology \\ Acclimation to water restriction implies different paces for behavioral and physiological responses in a lizard species \\ --Manuscript Draft--
}

\begin{tabular}{|c|c|}
\hline Manuscript Number: & 19062R2 \\
\hline Article Type: & Research Paper \\
\hline \multicolumn{2}{|l|}{$\begin{array}{l}\text { Corresponding Author Secondary } \\
\text { Information: }\end{array}$} \\
\hline Corresponding Author's Institution: & Sorbonne Universite \\
\hline \multicolumn{2}{|l|}{$\begin{array}{l}\text { Corresponding Author's Secondary } \\
\text { Institution: }\end{array}$} \\
\hline \multicolumn{2}{|l|}{ First Author Secondary Information: } \\
\hline \multirow[t]{6}{*}{ Order of Authors: } & David Rozen-Rechels \\
\hline & Andréaz Dupoué \\
\hline & Sandrine Meylan \\
\hline & Kenza Qitout \\
\hline & Beatriz Decencière \\
\hline & Simon Agostini \\
\hline
\end{tabular}


1 Acclimation to water restriction implies different paces for behavioral and physiological

2 responses in a lizard species

3

4 Running title: Behavioral and physiological responses to water restriction

5 Keywords: body temperature; water availability; activity; evaporative water loss; exploration;

6 metabolism; reptiles

7 What is already known: Recent studies on dry-skinned terrestrial ectotherms have shown that behavioral

8 and physiological responses to chronic changes in water availability (acclimation responses) are crucial

9 determinants of their resilience to global changes. The acclimation response is in general a multi-faceted

10 process that involves a range of traits with different sensitivities and paces of response. Unfortunately,

11 quantification of joint behavioral and physiological acclimation responses to chronic water stress are rare and

12 the relative importance of each response mechanism still remains to be elucidated.

13 What the study adds: Our results confirm a sequential acclimation response involving short-term

14 behavioral adjustments followed by delayed sex-specific changes of thermal preferences (thermal

15 depression) and of water loss rates (a reduction of cutaneous water loss). This study highlights the

16 importance of jointly quantifying behavior and physiology in order to understand acclimation responses in

17 wild animals. 


\section{Abstract}

19 Chronic changes in climate conditions may select for acclimation responses in terrestrial animals

20 living in fluctuating environments and beneficial acclimation responses may be key to the resilience

21 of these species to global changes. Despite evidence that climate warming induces changes in water

22 availability, acclimation responses to water restriction are understudied relative to thermal

23 acclimation. In addition, acclimation responses may involve different modes, paces and trade-offs

24 between physiological and behavioral traits. Here, we tested the dynamical acclimation responses of

25 a dry-skinned terrestrial ectotherm to a chronic water restriction. Yearling common lizards (Zootoca

26 vivipara) were exposed to a sub-lethal water restriction during 2 months of the summer season in

27 laboratory conditions, then released in outdoor conditions for 10 additional months. Candidate

28 behavioral (exploration, basking, and thermal preferences) and physiological traits (metabolism at

29 rest and standard water loss rate) potentially involved in the acclimation response were measured

30 repeatedly during and after water restriction. We observed a sequential acclimation response in

31 water restricted animals (yearlings spent less time basking during the first weeks of water

32 deprivation) which was followed by delayed sex-specific physiological consequences of the water

33 restriction during the following months (thermal depression in males and lower standard

34 evaporative water loss rates in females). Despite short-term negative effects of water restriction on

35 body growth, annual growth, survival and reproduction were not significantly different between

36 water restricted and control yearlings. This demonstrates that beneficial acclimation responses to

37 water restriction involve both short-term flexible behavioral responses and delayed changes in

38 thermal and water biology traits. 


\section{Introduction}

40 Adaptive plasticity is essential for organisms to cope with spatio-temporal variability of their

41 environment and is often the leading mechanism by which they can face the negative ecological

42 impacts of ongoing and future global changes (Somero 2010; Kelly et al. 2012; Seebacher et al.

43 2015; Wong and Candolin 2015). In particular, thermal plasticity refers to the capacity to adjust

44 phenotypes to changes in thermal conditions and is a major component of species' climate warming

45 resistance (Sinervo et al. 2010; Gunderson and Stillman 2015; Mitchell et al. 2018). Global changes

46 also entail modifications of rainfall regimes or drought events and therefore water availability in the

47 environment (Field et al. 2012). Water is a critical resource for most terrestrial animals, altering, for

48 example, their locomotor performances (Cheuvront and Kenefick 2014; Anderson and Andrade

49 2017) and life history strategies (Lorenzon et al. 2001; Marquis et al. 2008). Terrestrial organisms

50 have therefore evolved numerous plastic strategies to cope with spatial and temporal variation in

51 water availability, hereafter referred to as the hydroregulation tactics (Ostwald et al. 2016; Eto et al.

52 2017; Pirtle et al. 2019). Hydroregulation tactics play a key role in the water balance regulation (i.e.

53 the balance between water inputs and water losses) and the plasticity of hydroregulation tactics will

54 be as critical as thermal plasticity to predict the consequences of global changes on organisms (e.g.,

55 Peterman and Semlitsch 2014; Kearney et al. 2018).

56 Chronic changes in water availability or water losses induced by predictable seasonal fluctuations in rainfall and temperature or by sustained weather events (e.g., warm spells) may lead to acclimation responses in terrestrial animals. These acclimation responses may allow organisms to reduce the costs of performance loss associated with dehydration, and thus be beneficial in their response to

60 environmental changes in water balance regulation (i.e. beneficial acclimation hypothesis, Leroi et

61 al. 1994; Huey et al. 1999;, see Anderson and Andrade 2017 for an example). The acclimation

62 response of a given species is usually a multi-faceted process that involves a range of reversible 
morphological and physiological changes to maintain water balance, including modifications of

64 metabolic rates, adjustments in renal function and osmoregulation, modulations of cutaneous and

65 respiratory water loss rates, or adjustments of body temperature (Peterson 1996; McKechnie 2004;

66 Muir et al. 2007). In terrestrial ectothermic vertebrates, three important water-saving strategies are

67 metabolic depression (e.g., Muir et al. 2007), the reduction of trans-cutaneous evaporative water

68 loss (e.g., Anderson et al. 2017) and thermal depression (Ladyman and Bradshaw 2003). A

69 reduction of resting metabolism following chronic water deprivation is expected to reduce

70 respiratory water loss because metabolism scales linearly with ventilation rate (Woods and Smith

71 2010; Dupoué et al. 2017a). Another water conservation mechanism involves a decreased

72 permeability of the water barrier of the skin (Lillywhite 2006; McCormick and Bradshaw 2006).

73 Ectotherms may also respond to water restriction by thermal depression, that is, the lowering of

74 their preferred set temperature (Ladyman and Bradshaw 2003; Köhler et al. 2011; Anderson and

75 Andrade 2017). This is because higher body temperatures are associated with stronger respiratory

76 and cutaneous water loss rates during activity (e.g., Oufiero and Van Sant 2018; Senzano and

77 Andrade 2018). Previous studies focused mostly on one of these acclimation mechanisms, and their

78 prevalence or pace has been little investigated so far, especially in dry skinned ectotherms.

79 Physiological mechanisms involved in acclimation may be energetically or ecologically costly, and

80 cheaper alternative responses to cope with dehydration may consequently limit the implementation

81 of beneficial acclimation (Marais and Chown 2008; Huey et al. 2012). Relevant examples in

82 terrestrial animals are dispersal responses (i.e., behavioral flight) or changes in behavioral activity

83 and micro-habitat choice within the home range (i.e., behavioral fight responses consisting in

84 behavioral and physiological responses to cope with environmental changes while staying in the

85 same home range, inspired from Hertz et al. 1982), which may concur to increase water intake and

86 reduce water loss. In response to drought, individuals could enhance their exploration rate and 
87 locomotor activity to find more suitable hydric environments (e.g., Rozen-Rechels et al. 2018), or

88 on the contrary decrease activity and exposure to drying conditions (e.g., less basking) to reduce

89 water loss rates (e.g., Lorenzon et al. 1999; Davis and DeNardo 2010; Kearney et al. 2018).

90 Individuals can also select cooler and wetter micro-habitats (Guillon et al. 2013; Dupoué et al.

91 2015b; Pintor et al. 2016). Such flight and fight behavioral strategies are not mutually exclusive and

92 might take place relatively quickly, within hours or days after exposure to chronic water stress if

93 environmental conditions are conducive to behavioral plasticity (Huey et al. 2003; Rozen-Rechels

94 et al. 2018). According to the "Bogert effect" (Bogert 1949; Huey et al. 2003; Marais and Chown

95 2008), behavioral flexibility buffers environmental variations to which individuals are exposed and

96 should consequently reduce the benefits of physiological acclimation (i.e. "behavioral inertia"

97 evolutionary scenario, see (Huey et al. 2003; Muñoz and Losos 2018). Unfortunately, quantification

98 of joint behavioral and physiological acclimation responses to chronic water stress are rare and the

99 relative importance of each response mechanism is yet to be elucidated.

100 One intuitive alternative to the Bogert effect is that each trait response follows a distinct pace

101 whereby some physiological and behavioral responses come first, followed by other physiological

102 and behavioral adjustments. For example, physiological models of chronic stress responses in

103 vertebrates, such as the allostatic model (McEwen and Wingfield 2003) or the reactive scope model

104 (Romero et al. 2009), predict non-linear dynamics of behavioral, physiological and life history traits

105 when individuals are exposed to a chronic stressor. In these models, behavioral adjustments, being

106 less energetically costly, are expected on the short-term and facilitate the activation of an

107 emergency state. Examples of the kinetics of behavioral and physiological responses to chronic

108 stressors support this hypothesis (Timmerman and Chapman 2004; Romero and Wingfield 2015).

109 To our knowledge, no study to date has examined the kinetics of plastic responses to a chronic 
110 water deprivation in terrestrial animals, including potential long-lasting effects and fitness

111 responses.

112 In this study, we investigated temporal patterns of behavioral and physiological adjustments during

113 and after a chronic water restriction in the European common lizard, Zootoca vivipara (Lacertidae,

114 Lichtenstein, 1823). This species is widespread in Eurasia and depends on cold wetlands and

115 permanent access to free standing water for demographic persistence (Lorenzon et al. 2001; Dupoué

116 et al. 2017b). Acute or chronic exposure to sub-lethal water deprivation and reductions in water

117 availability in the habitat are associated with dehydration and physiological stress (Dupoué et al.

118 2017c, 2018a), a reduction in behavioral activity and body growth (Lorenzon et al. 1999), and some

119 behavioral flight responses (Rozen-Rechels et al. 2018). In addition, the potential reversal of

120 population growth to population decline is associated with increased habitat dryness and thermal

121 stress (Lorenzon et al. 2001; Dupoué et al. 2017b). Here, we compared morning activity patterns,

122 standard exploration behavior, thermal preferences, resting metabolic rates and standard water loss

123 rates from yearling lizards exposed to a 2-months water restriction period with those of yearlings

124 that had access to water ad libitum. During water restriction in the laboratory and after release in

125 outdoor enclosures, lizards were given opportunities to adjust their behavior. We predicted that a

126 chronic water restriction in this age class, characterized by a limited dispersal behavior and fast

127 growth linked with sexual maturation, will induce immediate water conservation behavioral

128 responses (shifts in activity patterns and less exploratory behaviors) together with delayed

129 physiological responses, including thermal and metabolic depression. We further predicted delayed

130 but potentially long-lasting reduction of standard water loss rates, especially from the skin, as a

131 consequence of water restriction.

132 Material and Methods

133 Study species, sampling and rearing conditions 
134 All common lizards were captured from captive populations maintained in $100 \mathrm{~m}^{2}$ outdoor

135 enclosures at the CEREEP-Ecotron IleDeFrance, France $\left(48^{\circ} 17^{\prime} \mathrm{N}, 2^{\circ} 41^{\prime} \mathrm{E}\right)$. Enclosures include a

136 natural vegetation layer with permanent access to free water and piles of rocks and logs for basking

137 and sheltering. Ground and avian predation are avoided with plastic walls and nets. The density of

138 the populations are similar (23 \pm 5 (SD) individuals, approximately $67 \%$ of yearlings). In these

139 enclosures, hibernation usually lasts from October to February-March and mating season starts

140 upon emergence of female individuals around March-April and lasts around 2 to 4 weeks. In our

141 study populations, age at maturation ranges from 1 (yearlings) to 2 years old.

142 In May 2016, 100 sexually immature yearlings (57 females and 43 males) were captured by hand in

14310 enclosures, identified by their unique toe-clip, and measured for snout-vent length (SVL \pm 1

$144 \mathrm{~mm})$ and body mass $\left(\mathrm{M}_{\mathrm{b}} \pm 1 \mathrm{mg}\right)$. Lizards were then housed in individual terraria $(18 \times 11 \times 12 \mathrm{~cm})$

145 with a shelter and sterilized peat soil as substratum. A basking site (around $35^{\circ} \mathrm{C}$ ), created using a

$14625 \mathrm{~W}$ bulb above the shelter, and light from a UVB 30W neon (Reptisun 10.0, white light) were

147 available for each terrarium 9 hours a day (from 09:00 to 18:00). Terraria were located in a

148 temperature-controlled room $\left(23^{\circ} \mathrm{C}\right.$ from 09:00 to $18: 00,16^{\circ} \mathrm{C}$ at night). In this set-up with a

149 thermal gradient and some microhabitat heterogeneity, lizard express a range of typical field

150 behaviors such as locomotor activity, basking and hiding in the shelter or in the soil. We therefore

151 expected that these conditions allowed for behavioral responses such as changes in daily activity

152 profiles, propensity of basking and hiding behaviors, or differences in body temperature.

153 Individuals were fed three times a week with $300 \pm 10 \mathrm{mg}$ of live house crickets (Acheta

154 domestica). Under normal housing conditions, water was available ad-libitum in a petri dish and

155 sprayed on one of the walls of the terrarium three times a day (09:00, 13:00 and 17:00). Individuals

156 were released in enclosures on August $1^{\text {st }}$ 2016. Individuals shared the enclosure with adults and

157 newly born juveniles (same density conditions in all enclosures: $41 \pm 3$ (SD), $72 \%$ of juveniles). 
158 From September $12^{\text {th }}$ to September $16^{\text {th }} 2016$, corresponding to the late summer activity season, we

159 recaptured as many individuals as we could (33 males and 40 females). We recaptured again all

160 survivors (recapture rate close to 100\%, Le Galliard et al. 2004) during the next reproductive season

161 from May $15^{\text {th }}$ to May $27^{\text {th }} 2017$ (32 males and 34 females). Non-recaptured individuals are

162 supposed to have not survived.

163 Water restriction manipulation

164 After acclimation of all individuals to standard housing conditions in late May 2016, we randomly assigned lizards to two experimental conditions of water availability (Lorenzon et al. 1999; Dupoué et al. 2018a; Rozen-Rechels et al. 2018) with a balanced sample of 29 females and 21 males in the water-restricted treatment and 28 females and 22 males in the control treatment. In the waterrestricted treatment, individuals were sprayed only once a day at 09:00, and the Petri dish providing water ad libitum was removed. These conditions mimic habitats in which water is only available with the morning dew during summer (Lorenzon et al. 1999, 2001; Dupoué et al. 2017b). This experimental water restriction has already been implemented in past studies during shorter periods

172 from a few days to two weeks. This protocol is sub-lethal but is known to enhance physiological

173 responses, although it is relatively less clear in yearlings compared to adults (Dupoué et al. 2018a).

174 It also enhances trans-generational and delayed effects in reproductive females (Dupoué et al.

175 2018a; Rozen-Rechels et al. 2018).

176 In the control treatment, water conditions remained similar to the normal ones described above.

177 These conditions mimic habitats with permanent access to water such as peat bogs or streams.

178 Water restriction treatment lasted from June $10^{\text {th }} 2016$ to July $31^{\text {st }} 2016$, which is equivalent to a 179 chronic early summer drought in natural populations (Dupoué et al. 2017b, 2018b). After that, 180 lizards were released in enclosures corresponding to common garden conditions. This would allow 181 us to test if effects of water restriction under laboratory conditions last in time. In case we did not 
182 find any, this set-up would allow us to test if individuals have different life-history trajectories

183 depending on the treatment they experienced in laboratory conditions. Individuals were split

184 randomly in 5 groups of 20 individuals each $(10$ control individuals and 10 water restricted

185 individuals) so that each group was measured on one day, (5 days total for one measurement

186 session). We defined 5 standard measurement sessions of behavioral and physiological data from

187 June $4^{\text {th }} 2016$ to June $8^{\text {th }} 2016$ (week 0, before water restriction), from July $2^{\text {nd }}$ to July $6^{\text {th }}$ (week 4 ,

188 one month later), from July $25^{\text {th }}$ to July $29^{\text {th }}$ (week 7 , two months later and before release in outdoor

189 enclosures), in September 2016 and in May 2017. The chronology of the measurements is

190 summarized in Figure 1.

191 Body mass and size measurements

192 Body mass $\left(\mathrm{M}_{\mathrm{b}}\right)$ provides a good indicator of hydration state in reptiles (Lillywhite et al. 2012;

193 Dupoué et al. 2015a, 2018a). Change in $\mathrm{M}_{b}\left(\Delta \mathrm{M}_{\mathrm{b}}\right)$ was calculated as the difference between initial

$194 \mathrm{M}_{\mathrm{b}}$ at the onset of experiment (week 0) and $\mathrm{M}_{\mathrm{b}}$ which was focally measured all over the water

195 restriction (weeks 1, 2, 4, 6, 7 and 8). In order to standardize measurements, $\mathrm{M}_{\mathrm{b}}$ was always

196 measured two days after a feeding event. To assess growth of structural size, snout-vent length

197 (SVL) was also measured in weeks 0 and 4 as well as in September 2016 and in May 2017.

198 Structural growth rate was then defined as the difference in SVL between two measurements

199 sessions divided by the number of days between those sessions. We calculated early growth during

200 the laboratory experiment (growth between week 0 and week 4; $\Delta$ SVLexperiment), summer growth

201 (growth between week 4 and September 2016; $\Delta \mathrm{SVL}_{\text {summer}}$ ), and annual growth (growth between

202 September 2016 and May 2017; $\Delta$ SVL $\left._{\text {annual }}\right)$.

\section{Behavioral tests}

204 We measured individual behavior at all standard sessions when lizards were in post-absorptive state.

205 Emergence time and basking effort in the home cage 
206 We scored lizards' behavior in their home cage during weeks 0, 1, 4 and 7. These measurements

207 were made for all 100 individuals in the same day. From 08:30 to 12:00, an observer recorded the

208 lizards' behavior in their cage every 15 mins (15 record per trial) with a minimum disturbance.

209 Behavioral items included: lizard hidden and inactive, lizard basking under the heat source, and any

210 other active behaviors (e.g., moving, scratching the soil). From this, we calculated emergence time

211 (first time the individual was seen active) and basking effort (proportion of observations seen

212 basking).

213 Exploration behavior in a neutral arena

214 In a temperature-controlled room at $25^{\circ} \mathrm{C}$, individuals were tested for their exploration behavior in

215 30-min tests between 09:00 and 11:30 in a neutral arena. Neutral arenas $(44.5 \times 24 \times 26 \mathrm{~cm})$

216 contained a layer of white sand as substrate and were warmed with a 40W light bulb heated basking

217 point. Two UVB 30W neon tubes were suspended above the arena to homogenize light conditions

218 and avoid phototropism. During the first 10 mins, individuals were allowed to habituate to the arena

219 and recover from handling stress (Rozen-Rechels et al. 2018). We then recorded their behaviors

220 using webcams set at 5 images per sec for 20 mins. Prior to each trial, sand layer was dried and

221 sterilized at $150^{\circ} \mathrm{C}$ for 2 hours in a stove and arenas were washed between each trial in order to

222 suppress conspecifics' odors from the arena. We extracted 12 behavioral units related to exploration

223 (detailed in Appendix 1) from the videos using the same protocol of image analysis as previously

224 described (Rozen-Rechels et al. 2018). We then used a multivariate analysis to calculate a

225 composite exploration score for each individual within each session (see Appendix 1 and Table A1

226 and (Rozen-Rechels et al. 2018) for the complete analytical procedure).

227 Thermal preferences in a neutral arena

228 We measured thermal preferences in a neutral thermal gradient $(80 \times 15 \times 20 \mathrm{~cm})$ filled with a

229 substratum of dried and sterilized peat soil. We placed a plate of wood on the ground (for basking 
230 and hiding) and installed a $40 \mathrm{~W}$ heat bulb $15 \mathrm{~cm}$ above the ground at the warm side of the gradient

$231\left(49.1 \pm 6.7^{\circ} \mathrm{C}\right)$. The cold side of the gradient was maintained at ambient temperature $\left(25.5 \pm 1.9^{\circ} \mathrm{C}\right)$.

232 A UVB 30W neon provided white, natural light conditions above each thermal gradient. Heat bulbs

233 were turned on at 12:00 for one hour before individuals were randomly placed in one out of 20

234 thermal gradients for habituation for 30 mins. Every 20 mins until 17:10 (12 measurements), skin

235 surface temperature $\left(T_{p}\right)$ of lizards was measured at the same focal distance $(\mathrm{ca} .30 \mathrm{~cm}$, i.e.

236 measurement in a $6 \mathrm{~mm}$ diameter circle, that we were able to assess thanks to three lasers indicating

237 the centre of the circle and the diameter of the spot when measuring the temperature) using an

238 infrared thermometer (Raytek, Raynger MX2). This method allows temperature measurements

239 without handling lizards, which are strongly correlated with core temperatures, and provides an

240 accurate measure of preferred body temperature (Bucklin et al. 2010; Artacho et al. 2013). We

241 analyzed preferred temperature in comparison to initial preferred temperatures at the onset of the

242 experiment. To do so, we calculated the difference between each skin surface temperature

243 measurement and the measurement done on the same individual and the same time of the day at

244 week 0 , hereafter referred to as $\Delta \mathrm{T}_{\mathrm{p}}$.

245 Metabolic rate and water losses

246 Resting metabolic rate (RMR) and total evaporative water loss (TEWL) were measured overnight at

$24725^{\circ} \mathrm{C}$ when individuals are normally inactive. We measured oxygen consumption $\left(\mathrm{VO}_{2}\right)$ using

248 closed-system respirometry methods as previously described (Foucart et al. 2014) and we measured

249 TEWL concomitantly. We weighed the lizards $\left(\mathrm{M}_{\mathrm{b} 1}\right)$ and let them acclimate at $25^{\circ} \mathrm{C}$ for $3 \mathrm{~h}$ in late

250 afternoon. After collecting a baseline air sample with adapted locked syringes at the onset of trial

251 (two $140 \mathrm{~mL}$ syringes, Medtronic Monoject Luer Lock), we closed the jar and placed the lizards for

$25212 \mathrm{~h}$ in a controlled climatic chamber (Aqualytic TC255). We collected a final air sample from each

253 container and weighted the lizard a second time $\left(\mathrm{M}_{\mathrm{b} 2}\right)$ to estimate body mass loss $\left(\mathrm{M}_{\mathrm{b} 2}-\mathrm{M}_{\mathrm{b} 1}\right)$. 
254 Oxygen proportion in air samples was determined using an $\mathrm{O}_{2}$ analyzer (FOXBOX, Sable Systems,

255 Las Vegas, NV, USA). Using an infusion pump (KDS 200, KD Scientific Inc., Holliston, MA,

256 USA), air was sent at a constant flow $\left(60 \mathrm{~mL} \cdot \mathrm{min}^{-1}\right)$, dried in a column of Drierite, and in the $\mathrm{O}_{2}$

257 analyzer, which was calibrated before each trial using outdoor air. Oxygen consumption (mL.h ${ }^{-1}$ )

258 was calculated as the difference between final $\mathrm{O}_{2}$ and baseline $\mathrm{O}_{2}$ multiplied by the exact chamber

259 volume ( $\mathrm{mL}$, calculated by measuring the mass of water it can contain) divided by trial duration $(\mathrm{h})$.

260 We also measured $\mathrm{CO}_{2}$ production $\left(\mathrm{mL} \cdot \mathrm{h}^{-1}\right)$ which was highly correlated to oxygen consumption

$261\left(\mathrm{R}^{2}=0.98\right)$. We calculated the respiratory exchange ration defined as the ratio between $\mathrm{CO}_{2}$

262 produced and $\mathrm{O}_{2}$ consumed which was not affected by the water restriction $\left(\mathrm{F}_{1,98}=0.04, p=0.83\right.$;

$263 \sim 0.7$ in yearlings, $\sim 0.8$ in adults).

264 TEWL $\left(\mathrm{mg} \cdot \mathrm{h}^{-1}\right.$ ) was calculated from body mass loss divided by the time between $\mathrm{M}_{\mathrm{b} 1}$ and $\mathrm{M}_{\mathrm{b} 2}$

265 measures, a method previously validated for this species (Dupoué et al. 2017c). RMR and TEWL

266 were measured in weeks 0,4 and 7 during the laboratory experiment (the night prior to behavioral

267 measurements) as well as in May 2017 at the end of the study (the night after behavioral

268 measurements in order to ensure the same post-prandial digestive state of individuals two days after

269 recapture). For each individual, as we expected physiological traits to change with time and within

270 individuals, we calculated the changes in RMR $(\triangle \mathrm{RMR})$ and TEWL $(\triangle \mathrm{TEWL})$ as the difference

271 between individual record of the measurement session and the one at week 0.

272 Statistical analyses

273 Statistical analyses were performed with R version 3.4.1 (R Core Team 2018). In most analyses,

274 trait variation was analyzed with ANCOVAs using linear models and backward model selection

275 from a full model including the three-way interaction between treatment, sex and time

276 (measurement session). In the cases of $\Delta \mathrm{M}_{\mathrm{b}}, \Delta \mathrm{SVL}, \Delta \mathrm{RMR}$ and $\Delta \mathrm{TEWL}$, initial value at the onset

277 of the experiment was included as fixed effect. For $\triangle \mathrm{RMR}$ and $\triangle \mathrm{TEWL}$, we included individual $\mathrm{M}_{\mathrm{b}}$ 
as a fixed effect in the ANCOVA to account for body mass scaling. Metabolism is indeed positively related to body mass (Gillooly et al. 2001) and water loss rates depend on the whole-body area and respiratory exchanges, both scaling with body mass. For $\triangle T E W L$, we also considered the presence of feces as fixed, categorical effect to account for corresponding mass loss due to defecation. We analyzed separately treatment effects during the laboratory experiment and delayed effects after recapture in outdoor enclosures, given the substantial changes in sample sizes and individual contribution between sessions. In the first three measurement sessions, we used linear mixed models (lme function from "nlme" package, Pinheiro et al. 2007) and set individual identity as a random factor to account for repeated measurements between sessions. Sessions in September 2016 and in May 2017 were investigated separately (one observation per individuals in each). We included enclosure identity as a random factor to account for among-enclosures variability. In all cases, the best model fit was determined using log-likelihood ratio tests (LRTs) and elimination of non-significant factors at $5 \%$ critical rate.

291 We analyzed variation in $\Delta \mathrm{T}_{\mathrm{p}}$ in a different way because body temperature was recorded

292 sequentially during the day and we wanted to account for potential daytime trends in thermal

293 preferences (Artacho et al. 2013). For laboratory sessions, the full mixed effect model thus included

294 a two-way interaction between treatment and sex and a three-way interaction between treatment,

295 measurement session and time of day. September 2016 and May 2017 thermal preferences were 296 analyzed in separate similar models.

297 We estimated whether or not the treatment impacted emergence time using Cox survival model 298 from the package "coxme" (Therneau 2018). By analogy to a survival analysis, at each observation, 299 an individual would emerge with a probability $P$ (“die"). If we did not have any observation of the 300 individual at the end of the experiment, we consider that it never went out ("survived"). The model 301 estimates the mean time of emergence. We analyzed the proportion of time spent basking by testing 
302 the influence of all possible two-ways interactions between treatment, session, and sex on the

303 number of basking events using generalized linear mixed models from the package "Ime4",

304 considering that the number of basking events is the result of a binomial probability distribution.

305 We controlled the family-wise error rate due to multiple comparisons by calculating the corrected

306 threshold of significance with the Holm-Bonferroni method based on the number of tests $m$ realized

307 at each step of the study (laboratory experiment: $m=8$, after one month in common gardens: $m=3$,

308 after winter in common gardens: $m=5$ ). In each case, $p$-values of significance of the treatment

309 effect were ranked according from the lowest to the highest and the new threshold was calculated as

$$
\alpha_{\text {Holm }}=\frac{0.05}{m+1-\text { rank }} \text { (Holm 1979). }
$$

\section{Results}

313 Initial $\mathrm{M}_{\mathrm{b}}, \mathrm{SVL}, \mathrm{T}_{\mathrm{b}}, \mathrm{RMR}$ and TEWL values (week 0, before the beginning of the water restriction)

314 are shown in Table 1.

315 Effects of water restriction on body mass and growth

316 Body mass increased on average during the laboratory manipulation $\left(\mathrm{F}_{5,490}=288.9, p<0.0001\right)$ but

317 with different temporal trends between treatments (treatment: $\mathrm{F}_{1,96}=28.5, \mathrm{p}<0.0001$; treatment $\times$

318 time: $\left.\mathrm{F}_{5,490}=10.6, p<0.0001, \alpha_{\mathrm{Holm}}=0.006\right)$. Water-restricted yearlings had a decreased $\Delta \mathrm{M}_{\mathrm{b}}$ one

319 week and two weeks after the beginning of the experiment, but this difference vanished in

320 subsequent sessions (Fig. $2 \mathrm{~A}$ ). In addition, males had a lower $\Delta \mathrm{M}_{\mathrm{b}}$ than females $\left(\mathrm{F}_{1,96}=4.47, \mathrm{p}=\right.$

$3210.037)$ and $\Delta \mathrm{M}_{\mathrm{b}}$ was negatively correlated to initial body mass $\left(\mathrm{F}_{1,96}=8.2, \mathrm{p}=0.005\right)$. During the

322 first month, water-restricted individuals had also a marginally lower $\Delta$ SVLexperiment compared to

323 control individuals $\left(\mathrm{F}_{1,96}=4.235, p=0.042, \alpha_{\mathrm{Holm}}=0.08\right.$; see Figure $\left.2 \mathrm{~B}\right)$. The treatment did not

324 affect $\Delta \mathrm{SVL}_{\text {summer }}$ and $\Delta \mathrm{SVL}_{\text {annual }}$ (all $p>0.59$, all $\alpha_{\text {Holm }}<0.05$; see Figure $2 \mathrm{~B}$ ). Males had 
325 consistently lower $\Delta$ SVL than females (all $p<0.007$ ) and $\Delta$ SVL was negatively correlated to initial

326 body size (all $p<0.002)$.

327 Emergence and basking effort in home cage

328 Time since the beginning of the experiment significantly explained variation in emergence behavior

$329\left(\chi^{2}=107.7, \mathrm{df}=3, p<0.0001\right)$, but treatment had no effect $\left(\chi^{2}=1.01, \mathrm{df}=1, \mathrm{p}=0.31, \alpha_{\text {Holm }}=\right.$

330 0.01, see Figure 3A). Basking effort was also influenced by time since the beginning of the

331 experiment but in interaction with water restriction treatment (treatment $\times$ time: $\chi^{2}=14.2, \mathrm{df}=3, \mathrm{p}$

$332=0.003, \alpha_{\text {Holm }}=0.007$; Fig. $\left.3 \mathrm{~B}\right)$ and in interaction with sex $\left(\right.$ time $\times$ sex: $\left.\chi^{2}=10.3, \mathrm{df}=3, \mathrm{p}=0.02\right)$.

333 One week after the beginning of the experiment, control yearlings spent significantly more time

334 basking than water-restricted individuals (Fig. 3B), whereas differences between treatments later

335 disappeared (all $p>0.25$ ). In addition, no sex differences existed during the first month (all $p>$

$3360.17)$ but males basked significantly less than females at the end of the experiment $(z=-3.18 ; p=$

$3370.001)$.

\section{Exploration score in neutral arenas}

339 Exploration score was lower on average one month and two months after the start of the experiment

340 than at the beginning of the study $\left(\mathrm{F}_{2,196}=10.84, p<0.0001\right)$ but there was no effect of water

341 restriction on exploration $\left(\mathrm{F}_{1,98}=0.13, p=0.72\right.$; treatment $\times$ time: $\mathrm{F}_{4,194}=0.91, p=0.40, \alpha_{\text {Holm }}=$

342 0.016; see Figure 4A). One month after the end of the experiment (September 2016), exploration

343 score was influenced by a two-way interaction between treatment and sex $\left(\mathrm{F}_{1,69}=5.7, p=0.02\right.$,

$\left.344 \alpha_{\text {Holm }}=0.017-0.025\right)$. Control females and males did not differ in their exploration rate $\left(t_{69}=1.57\right.$;

$345 p=0.12)$, nor did control and water-restricted females $\left(t_{69}=1.78 ; p=0.08\right)$. However, water-

346 restricted males explored their environment significantly less than control males $\left(t_{69}=-2.38 ; p=\right.$

347 0.02). One year later, water restriction treatment had no effect on exploration score $\left(F_{1,64}=0.02, p=\right.$

$\left.3480.9, \alpha_{\text {Holm }}=0.05\right)$. 
350 Preferred body temperature did not change significantly during the laboratory study $\left(F_{1,2273}=1.73\right.$, $351 p=0.19)$ nor between treatments $\left(F_{1,98}=0.26, p=0.61\right.$; treatment $\times$ time: $F_{1,2273}=0.23, p=0.63$,

$352 \alpha_{\text {Holm }}=0.05$; see Figure 4B). One month after the end of the laboratory study, intra-individual $\Delta T_{p}$ 353 was influenced by a two-way interaction between sex and treatment $\left(F_{1,69}=5.74, p=0.02, \alpha_{\text {Holm }}=\right.$ $3540.017-0.025$; see Figure 4B) as well as by time of day $\left(F_{1,802}=7.94, \mathrm{p}=0.005\right)$. At this stage, 355 water restriction did not change thermal preferences of females $\left(t_{69}=0.38, p=0.47\right)$ but decreased 356 the thermal preferences of males $\left(t_{69}=-2.39, p=0.02\right)$. One year later, we found no effect of 357 treatment conditions $\left(F_{1,64}=0.26, \mathrm{p}=0.61, \alpha_{\mathrm{Holm}}=0.017\right)$.

\section{Standard metabolism and water losses}

359 During the laboratory experiment, $\Delta$ RMR was negatively related to initial values $\left(F_{1,97}=21.3, p<\right.$ 3600.0001 ) but independent of treatment and session groups (treatment: $F_{1,97}=2.23, p=0.14$;

361 treatment $\times$ time: $\left.F_{1,97}=0.25, p=0.62, \alpha_{\text {Holm }}=0.025\right)$ and sex $\left(\right.$ treatment $\times$ sex: $F_{1,95}=1.15, p=$ 362 0.29). $\triangle \mathrm{RMR}$ measured from metabolic rate at recapture during the next reproductive season was marginally lower in water-restricted yearlings $\left(F_{1,59}=3.66, p=0.061, \alpha_{\mathrm{Holm}}=0.0125\right.$; see Figure $5 \mathrm{~A})$. In addition, changes in evaporative water loss ( $\triangle \mathrm{TEWL})$ decreased during the laboratory experiment $\left(\mathrm{F}_{1,96}=28.5, p<0.0001\right.$; see Figure 5B) independently from the treatment (treatment: $F_{1,97}=1.64, p=0.20$; treatment $\times$ time: $\left.F_{1,96}=0.75, p=0.39, \alpha_{\text {Holm }}=0.01\right) . \Delta$ TEWL at recapture during the next reproductive season was significantly explained by a two-way interaction between sex and treatment $\left(F_{1,48}=4.35, p=0.04, \alpha_{\mathrm{Holm}}=0.01\right.$; see Figure $\left.5 \mathrm{~B}\right)$. Water-restricted females had lower $\Delta$ TEWL than control females $\left(t_{48}=-2.69, p=0.01\right)$, whereas no treatment effect was detected in males $\left(t_{48}=0.33, p=0.75\right)$. In all cases, $\Delta$ TEWL was negatively correlated to the initial TEWL value (all $p<0.0001$ ). $\triangle$ TEWL during the laboratory experiment were positively correlated to body mass $(p=0.0001)$. 


\section{Discussion}

374 We exposed yearling lizards to a sub-lethal, chronic water restriction episode lasting almost two

375 months during which lizards could substantially buffer dehydration with behavioral shifts. Our data

376 revealed acclimation kinetics of the behavioral and physiological responses to water deprivation.

377 The kinetics of these behavioral and physiological responses were generally in agreement with our

378 initial predictions since flexible behavioral changes came first, followed by delayed sex-specific

379 acclimation responses in thermal physiology (thermal depression) and standard evaporative water

380 loss. However, in contrast to our expectations, we did not find any short-term thermoregulation

381 adjustments in our laboratory setting. Despite significant short-term negative effects of water

382 deprivation on body mass change and marginal negative effects on body size growth during the first

383 weeks of manipulation, which could suggest short-term physiological adjustments that we did not

384 measure, the annual life-history strategy of sub-adult lizards from the two treatments did not differ

385 for total annual size growth, nor for annual survival (see Appendix 2) and future reproduction of

386 females (see Appendix 3). Differences in body mass change might be the consequence of

387 differences in muscle volume (storing water and sources of metabolic water) or differences in

388 hydration state. We thus conclude that phenotypic plasticity in Z. vivipara compensates to some

389 degree for the homeostatic load imposed by dehydration risk. This supports the beneficial

390 acclimation hypothesis, at least in our laboratory setting (Huey et al. 1999, Kelly et al. 2012) and

391 the kinetics is consistent with previous studies on acclimation to other stressors. In the sailfin molly

392 Poecilia latipinna, fishes exposed to extreme hypoxia display an immediate physiological response

393 (increased ventilation) and an immediate behavioral response (increased aquatic surface respiration)

394 that decreases over time as gradual acclimation processes take place (e.g., changes in hemoglobin

395 concentration, Timmerman and Chapman 2004). Testing whether observed adjustments give 
significant advantages in the water-restricted environment would however be necessary to strictly conclude that we observe beneficial acclimation.

Immediate behavioral responses to water restriction included a sharp reduction of basking activity, which was paralleled by a reduction of body size growth. In ectothermic species, an increase of thermoregulation effort and high body temperatures closed to thermal preferences would increase water loss rates compared to resting conditions. A reduction of basking effort can therefore be interpreted as a water-conservation strategy (Lourdais et al. 2017). This reduction to conserve water can however conflict with energy intake and allocation to structural growth or reserves (Adolph and Porter 1993; Niewiarowski 2001). Similar results were observed in a previous comparative study with wild-caught yearlings from dry and humid natural habitats: lizards were also less active after a one-month long water scarcity and grew slower in the laboratory, and the spatial variation in growth rates observed between wet and dry natural habitats paralleled the results of the laboratory study (Lorenzon et al. 1999, 2001). During the same time period of our laboratory manipulation, we found no plastic changes for thermal preferences, resting metabolism and standard water loss rates, which were expected considering recent studies on other ectotherms (Muir et al. 2007; Anderson and Andrade 2017; Anderson et al. 2017). This may suggest a Bogert effect, as short-term changes in a key behavioral trait, here basking activity, compensated for the environmental changes induced

413 by water restriction and protected individuals from its deleterious effects. We, however, cannot exclude that other physiological responses we did not measure in our study were stimulated by water deprivation (e.g., shift from carbohydrates to protein catabolism to increase metabolic water

416 production, see Brusch et al. 2016 or hormone-induced changes in renal function and

417 osmoregulation to save water lost in urine and feces, see McCormick and Bradshaw 2006). In

418 addition, some traits may not respond because yearling lizards generally have lower water

419 requirements than adults and are therefore less sensitive to water restriction than older lizards 
420 (Dupoué et al. 2018a). In support of this hypothesis, no difference in basking activity was detected

421 after the first month of water deprivation and therefore no Bogert effect was expected. Yet, we

422 found no acclimation response for other behavioral or physiological traits during the second half of

423 the laboratory experiment and water-restricted individuals caught up their growth delay. This

424 suggests that fast and reversible physiological adjustments took place.

425 We predicted delayed responses for some physiological traits but did not expect specifically delayed 426 sex-specific effects of water restriction on exploration behavior and thermal preferences at the end

427 of summer, as observed in male yearlings in this study. Based on a previous study of water-

428 dependent exploration behavior (Rozen-Rechels et al. 2018) and outcomes of thermal acclimation

429 experiments (Clusella-Trullas and Chown 2014), we instead assumed that exploration and, to some

430 extent, thermal preferences would be more flexible and would respond earlier following water

431 deprivation (e.g., (Rozen-Rechels et al. 2018). The delayed responses found in males are concordant

432 with a water conservation strategy (i.e., fight response, aiming at buffering the effects of the

433 environmental constraints on the physiology) since lower exploration scores and thermal depression

434 imply lower rates of water loss from locomotor activities and from trans-cutaneous evaporation

435 (Lourdais et al. 2017). The high sensitivity of male common lizards to weather conditions has

436 already been demonstrated in previous studies (Le Galliard et al. 2006; Dupoué et al. 2018a), and is

437 also consistent with recent results showing lower growth rate in juvenile males exposed to

438 abnormally hot summers (Dupoué et al. 2019). Interestingly, during the time period when yearlings

439 were maintained in enclosures in late summer 2016, the study site experienced an abnormal heat

440 wave characterized by very low precipitation in August and a warmer and drier month of September

441 than average (Meteo France: $+0.9^{\circ} \mathrm{C}$ for August average temperature,$+2.4^{\circ} \mathrm{C}$ for September and

442 rain deficits of $60 \%$ in August and $>30 \%$ in September compared to previous years). Thus, one

443 possibility is that the delayed acclimation responses were caused by "a facilitation process", 
444 whereby a new environmental stressor (here a hot and dry summer) causes a higher than expected

445 stress response in animals that were exposed to past stressful conditions (here the laboratory water

446 deprivation, see (Trompeter and Langkilde 2011) for an example of facilitation response to

447 predation stress in a lizard). To test this hypothesis, future studies independently manipulating the

448 environmental conditions experienced by male yearlings in two successive later stages are needed.

449 Another negative delayed effect of water restriction was found for standard water loss rates in

450 female lizards the year after the laboratory experiment, when females had reached sexual maturity

451 and were all gravid. Variations of TEWL were positive, which can be explained by the higher mass

452 of individuals at the adult stage. Water-restricted females had however lower change of TEWL than

453 control ones. This effect is weak and need further confirmation and should therefore be cautiously

454 interpreted but is also consistent to a water conservation strategy. Since metabolic rates and body

455 size were not different between water restricted and control females during this time period, we

456 assume that these differences might reflect changes in cutaneous water loss rates and therefore

457 probably cutaneous resistance to water loss between water restricted and control females. This

458 explanation is also supported by the robustness of the result of our statistical analyses of TEWL to

459 inclusion of $\triangle \mathrm{RMR}$ (changes in metabolism, hence ventilation rates) as a covariate, indicating that

460 water restriction changes total water loss rates even after corrections for differences in respiratory

461 activity (see Table A2). This slight change in standard water loss rates supports our initial prediction

462 of a water-conservation strategy. Other studies that have tested for plastic changes in cutaneous

463 water loss rates generally found that lizards or snakes acclimated to drier environments or water

464 restricted environments can adjust cutaneous water loss rates within days or weeks of exposure

465 (Kobayashi et al. 1983; Kattan and Lillywhite 1989; Moen et al. 2005 but see Neilson 2002;

466 Gunderson et al. 2011). Reduction of cutaneous water loss rates is also well documented in anurans

467 exposed to chronic water deprivation (Anderson et al. 2017; Senzano and Andrade 2018). It is 
generally accepted that the skin resistance to water loss depends mainly on the intracellular lipid content and ultrastructure of the mesos layer of the epidermis (reviewed by Lillywhite 2006).

470 Further investigations of skin properties would be necessary to know what are the mechanisms underlying delayed acclimation patterns in the common lizard. This female-specific acclimation response of skin properties may be explained by the stronger reliance of females on water during gestation and embryonic development in this viviparous species (Dupoué et al. 2015a, 2018a).

In conclusion, the results of our multivariate analysis of the physiological and behavioral responses to chronic water deprivation in the common lizard are broadly speaking consistent with general predictions about the kinetics of a long-term acclimation process and stress response (Huey et al. 1999; Romero and Wingfield 2015). According to this framework, less costly and more flexible adjustments of daily behavioral routines should occur first followed by delayed responses in thermal preferences, metabolism and eventually cutaneous water loss rates (e.g., Timmerman and Chapman 2004). Such dynamical changes may lead to an "emergency life history stage" (sensu Wingfield et al. 1998) that promotes survival in the face of a challenging environment as seen in this study where water restricted lizards had similar annual growth, survival and reproduction than control lizards. Traits involved in acclimation responses were those most strongly linked to thermoregulation (basking and thermal preferences), but we found no evidence of metabolic depression, although this a widespread response to water restriction and energy intake reduction in endotherms (Ruf and Geiser 2015) and dry-skinned ectotherm (Christian et al. 1996a, 1996b). Our results are partly consistent with biophysical models predicting that hydroregulation responses would rely mostly on evaporative water loss changes but also activity pattern changes, and not metabolic depression (Pirtle et al. 2019). Surprisingly, we found sex-specific acclimation responses,

490 in line with previous findings (e.g., (Dupoué et al. 2018a), which could be explained by ecological 491 and physiological differences between males and females. Interestingly, males seem more 
susceptible to water restriction than females as previous findings might suggest (Le Galliard et al.

493 2006; Dupoué et al. 2019). This study illustrates the complexity of acclimation responses to water

494 restriction in dry-skinned terrestrial ectotherms.

\section{References}

Adolph S.C. and W.P. Porter. 1993. Temperature, activity, and lizard life histories. Am Nat 142:273295.

Anderson R.C.O. and D.V. Andrade. 2017. Trading heat and hops for water: Dehydration effects on locomotor performance, thermal limits, and thermoregulatory behavior of a terrestrial toad. Ecol Evol 7:9066-9075.

Anderson R.C.O., R.P. Bovo, C.E. Eismann, A.A. Menegario, and D.V. Andrade. 2017. Not good, but not all bad: dehydration effects on body fluids, organ masses, and water flux through the skin of Rhinella schneideri (Amphibia, Bufonidae). Physiol Biochem Zool 90:313-320.

Artacho P., I. Jouanneau, and J.-F. Le Galliard. 2013. Interindividual variation in thermal sensitivity of maximal sprint speed, thermal behavior, and resting metabolic rate in a lizard. Physiol Biochem Zool 86:458-469.

Bates D., M. Mächler, B. Bolker, and S. Walker. 2015. Fitting Linear Mixed-Effects Models Using lme4. Journal of Statistical Software 67:1-48.

Bogert C.M. 1949. Thermoregulation in reptiles, a factor in evolution. Evolution 3:195-211.

Brusch G.A., E.N. Taylor, and S.M. Whitfield. 2016. Turn up the heat: thermal tolerances of lizards at La Selva, Costa Rica. Oecologia 180:325-334.

Bucklin S.E., G.W. Ferguson, W.H. Gehrmann, and J.E. Pinder. 2010. Use of remote laser sensing equipment to measure surface temperature and to predict deep body temperatures of small lizards in the field. Herpetol Rev 41:309-312. 
515 Cheuvront S.N. and R.W. Kenefick. 2014. Dehydration: physiology, assessment, and performance $516 \quad$ effects. Compr Physiol 4:257-285.

517 Christian K., B. Green, G. Bedford, and K. Newgrain. 1996a. Seasonal metabolism of a small, 518 arboreal monitor lizard, Varanus scalaris, in tropical Australia. Journal of Zoology 240:383519396.

520 Christian K.A., A.D. Griffiths, and G.S. Bedford. 1996b. Physiological ecology of frillneck lizards in a seasonal tropical environment. Oecologia 106:49-56.

522 Clusella-Trullas S. and S.L. Chown. 2014. Lizard thermal trait variation at multiple scales: a review. J Comp Physiol B 184:5-21.

524 Davis J.R. and D.F. DeNardo. 2010. Seasonal Patterns of Body Condition, Hydration State, and Activity of Gila Monsters (Heloderma suspectum) at a Sonoran Desert Site. J Herpetol

Dray S., A.-B. Dufour, and others. 2007. The ade4 package: implementing the duality diagram for 44:83-93.

529 Dupoué A., F. Brischoux, F. Angelier, D.F. DeNardo, C.D. Wright, and O. Lourdais. 2015a. Intergenerational trade-off for water may induce a mother-offspring conflict in favour of embryos in a viviparous snake. Funct Ecol 29:414-422.

532 Dupoué A., F. Brischoux, and O. Lourdais. 2017a. Climate and foraging mode explain interspecific variation in snake metabolic rates. Proc Roy Soc B-Biol Sci 284:20172108.

534 Dupoué A., J.-F.L. Galliard, R. Josserand, D.F. DeNardo, B. Decencière, S. Agostini, C. Haussy, et al. 2018a. Water restriction causes an intergenerational trade- off and delayed motheroffspring conflict in a viviparous lizard. Funct Ecol 32:676-686. 
Dupoué A., O. Lourdais, S. Meylan, F. Brischoux, F. Angelier, D. Rozen- Rechels, Y. Marcangeli, et al. 2019. Some like it dry: Water restriction overrides heterogametic sex determination in two reptiles. Ecology and Evolution 9:6524-6533.

Dupoué A., A. Rutschmann, J.F. Le Galliard, J. Clobert, F. Angelier, C. Marciau, S. Ruault, et al. 2017b. Shorter telomeres precede population extinction in wild lizards. Sci Rep 7.

Dupoué A., A. Rutschmann, J.F. Le Galliard, J. Clobert, P. Blaimont, B. Sinervo, D.B. Miles, et al. 2018b. Reduction in baseline corticosterone secretion correlates with climate warming and drying across wild lizard populations. (K. Marske, ed.)J Anim Ecol 87:1331-1341.

Dupoué A., A. Rutschmann, J.F. Le Galliard, D.B. Miles, J. Clobert, D.F. DeNardo, G.A. Brusch, et al. 2017c. Water availability and environmental temperature correlate with geographic variation in water balance in common lizards. Oecologia 185:561-571.

Dupoué A., Z.R. Stahlschmidt, B. Michaud, and O. Lourdais. 2015b. Physiological state influences evaporative water loss and microclimate preference in the snake Vipera aspis. Physiol Behav 144:82-89.

Eto E.C., P.C. Withers, and C.E. Cooper. 2017. Can birds do it too? Evidence for convergence in evaporative water loss regulation for birds and mammals. Proc Roy Soc B-Biol Sci 284:20171478.

Field C.B., V. Barros, T.F. Stocker, and Q. Dahe. 2012. Managing the risks of extreme events and disasters to advance climate change adaptation: special report of the intergovernmental panel on climate change. Cambridge University Press.

Foucart T., O. Lourdais, D.F. DeNardo, and B. Heulin. 2014. Influence of reproductive mode on metabolic costs of reproduction: insight from the bimodal lizard Zootoca vivipara. J Exp Biol 217:4049-4056. 
560 Gillooly J.F., J.H. Brown, G.B. West, V.M. Savage, and E.L. Charnov. 2001. Effects of size and temperature on metabolic rate. Science 293:2248-2251.

562 Guillon M., G. Guiller, D.F. DeNardo, and O. Lourdais. 2013. Microclimate preferences correlate with contrasted evaporative water loss in parapatric vipers at their contact zone. Can J Zool

Gunderson A.R. and J.H. Stillman. 2015. Plasticity in thermal tolerance has limited potential to buffer ectotherms from global warming. Proc Roy Soc B-Biol Sci 282:20150401.

Hertz P.E., R.B. Huey, and E. Nevo. 1982. Fight versus flight: Body temperature influences defensive responses of lizards. Animal Behaviour 30:676-679.

Huey R.B., D. Berrigan, G.W. Gilchrist, and J.C. Herron. 1999. Testing the adaptive significance of acclimation: a strong inference approach. Am Zool 39:323-336.

Huey R.B., P.E. Hertz, and B. Sinervo. 2003. Behavioral drive versus behavioral inertia in evolution: a null model approach. Am Nat 161:357-366.

Huey R.B., M.R. Kearney, A. Krockenberger, J.A. Holtum, M. Jess, and S.E. Williams. 2012. Predicting organismal vulnerability to climate warming: roles of behaviour, physiology and adaptation. Phil Trans R Soc Lond B 367:1665-1679.

Kattan G.H. and H.B. Lillywhite. 1989. Humidity acclimation and skin permeability in the lizard Anolis carolinensis. Physiol Zool 62:593-606.

Kearney M.R., S.L. Munns, D. Moore, M. Malishev, and C.M. Bull. 2018. Field tests of a general ectotherm niche model show how water can limit lizard activity and distribution. Ecol Monogr 88:672-693. 
Kelly S.A., T.M. Panhuis, and A.M. Stoehr. 2012. Phenotypic plasticity: molecular mechanisms and

adaptive significance. Compr Physiol 2:1417-1439.

Kobayashi D., W.J. Mautz, and K.A. Nagy. 1983. Evaporative water loss: humidity acclimation in Anolis carolinensis lizards. Copeia 1983:701.

Köhler A., J. Sadowska, J. Olszewska, P. Trzeciak, O. Berger-Tal, and C.R. Tracy. 2011. Staying warm or moist? Operative temperature and thermal preferences of common frogs (Rana temporaria), and effects on locomotion. Herpetol J 21:17-26.

Ladyman M. and D. Bradshaw. 2003. The influence of dehydration on the thermal preferences of the Western tiger snake, Notechis scutatus. J Comp Physiol B 173:239-246.

Le Galliard J.-F., J. Clobert, and R. Ferriere. 2004. Physical performance and Darwinian fitness in lizards. Nature 432:502-505.

Le Galliard J.-F., M. Massot, M.M. Landys, S. Meylan, and J. Clobert. 2006. Ontogenic sources of variation in sexual size dimorphism in a viviparous lizard. J Evol Biol 19:690-704.

Leroi A.M., A.F. Bennett, and R.E. Lenski. 1994. Temperature acclimation and competitive fitness: an experimental test of the beneficial acclimation assumption. Proc Nat Acad Sci 91:19171921.

Lillywhite H.B. 2006. Water relations of tetrapod integument. J Exp Biol 209:202-226.

Lillywhite H.B., F. Brischoux, C.M. Sheehy, and J.B. Pfaller. 2012. Dehydration and drinking responses in a pelagic sea snake. Integr Comp Biol 52:227-234.

Lorenzon P., J. Clobert, and M. Massot. 2001. The contribution of phenotypic plasticity to adaptation in Lacerta vivipara. Evolution 55:392-404.

Lorenzon P., J. Clobert, A. Oppliger, and H. John-Alder. 1999. Effect of water constraint on growth rate, activity and body temperature of yearling common lizard (Lacerta vivipara). Oecologia 118:423-430. 
608 Lourdais O., A. Dupoué, M. Guillon, G. Guiller, B. Michaud, and D.F. DeNardo. 2017. Hydric "costs" of reproduction: pregnancy increases evaporative water loss in the snake Vipera aspis. Physiol Biochem Zool 90:663-672.

611 Marais E. and S.L. Chown. 2008. Beneficial acclimation and the Bogert effect. Ecol Lett 11:10271036.

613 Marquis O., M. Massot, and J.F. Le Galliard. 2008. Intergenerational effects of climate generate cohort variation in lizard reproductive performance. Ecology 89:2575-2583.

615 McCormick S.D. and D. Bradshaw. 2006. Hormonal control of salt and water balance in vertebrates. Gen Comp Endocr 147:3-8.

617 McEwen B.S. and J.C. Wingfield. 2003. The concept of allostasis in biology and biomedicine.

$618 \quad$ Horm Behav 43:2-15.

619 McKechnie A.E. 2004. Partitioning of evaporative water loss in white-winged doves: plasticity in response to short-term thermal acclimation. J Exp Biol 207:203-210.

621 Mitchell D., E.P. Snelling, R.S. Hetem, S.K. Maloney, W.M. Strauss, and A. Fuller. 2018. Revisiting concepts of thermal physiology: Predicting responses of mammals to climate change. $\mathrm{J}$

624 Moen D.S., C.T. Winne, and R.N. Reed. 2005. Habitat-mediated shifts and plasticity in the evaporative water loss rates of two congeneric pit vipers (Squamata, Viperidae, Agkistrodon). Evol Ecol Res 7:759-766.

627 Muir T.J., J.P. Costanzo, and R.E. Lee. 2007. Osmotic and metabolic responses to dehydration and urea-loading in a dormant, terrestrially hibernating frog. J Comp Physiol B 177:917-926.

629 Muñoz M.M. and J.B. Losos. 2018. Thermoregulatory behavior simultaneously promotes and 630 forestalls evolution in a tropical lizard. Am Nat 191:E15-E26. 
631 Neilson K.A. 2002. Evaporative water loss as a restriction on habitat use in endangered New Zealand endemic skinks. J Herpetol 36:342-348.

633 Niewiarowski P.H. 2001. Energy budgets, growth rates, and thermal constraints: toward an 634 integrative approach to the study of life- history variation. Am Nat 157:421-433.

635 Ostwald M.M., M.L. Smith, and T.D. Seeley. 2016. The behavioral regulation of thirst, water 636 collection and water storage in honey bee colonies. J Exp Biol 219:2156-2165.

637 Oufiero C.E. and M.J. Van Sant. 2018. Variation and repeatability of cutaneous water loss and skin resistance in relation to temperature and diel variation in the lizard Sceloporus consobrinus. J Comp Physiol B 188:671-681.

640 Peterman W.E. and R.D. Semlitsch. 2014. Spatial variation in water loss predicts terrestrial salamander distribution and population dynamics. Oecologia 176:357-369.

642 Peterson C.C. 1996. Anhomeostasis: seasonal water and solute relations in two populations of the desert tortoise (Gopherus agassizii) during chronic drought. Physiol Zool 69:1324-1358.

644 Pinheiro J., D. Bates, S. DebRoy, D. Sarkar, and R.C. Team. 2007. Linear and nonlinear mixed effects models. R package version 3:57.

646 Pintor A.F.V., L. Schwarzkopf, and A.K. Krockenberger. 2016. Hydroregulation in a tropical dryskinned ectotherm. Oecologia 182:925-931.

648 Pirtle E.I., C.R. Tracy, and M.R. Kearney. 2019. Hydroregulation. A neglected behavioral response of lizards to climate change? Pp. 343-374 in Behavior of Lizards: Evolutionary and Mechanistic Perspectives. CRC Press.

651 R Core Team. 2018. R: language and environment for statistical computing. R Foundation for 652 Statistical Computing, 2005; Vienna, Austria.

653 Romero L.M., M.J. Dickens, and N.E. Cyr. 2009. The reactive scope model - A new model integrating homeostasis, allostasis, and stress. Horm Behav 55:375-389. 
655 Romero L.M. and J.C. Wingfield. 2015. Tempests, poxes, predators, and people: stress in wild animals and how they cope. Oxford University Press.

657 Rozen-Rechels D., A. Dupoué, S. Meylan, B. Decencière, S. Guingand, and J.-F. Le Galliard. 2018. 658 Water restriction in viviparous lizards causes transgenerational effects on behavioral anxiety and immediate effects on exploration behavior. Behav Ecol Sociobiol 72:23.

660 Ruf T. and F. Geiser. 2015. Daily torpor and hibernation in birds and mammals. Biol Rev 90:891661 926.

662 Seebacher F., C.R. White, and C.E. Franklin. 2015. Physiological plasticity increases resilience of ectothermic animals to climate change. Nat Clim Change 5:61-66.

664 Senzano L.M. and D.V. Andrade. 2018. Temperature and dehydration effects on metabolism, water uptake and the partitioning between respiratory and cutaneous evaporative water loss in a

Sinervo B., F. Méndez-de-la-Cruz, D.B. Miles, B. Heulin, E. Bastiaans, M.V.-S. Cruz, R. LaraResendiz, et al. 2010. Erosion of lizard diversity by climate change and altered thermal niches. Science 328:894-899.

Somero G.N. 2010. The physiology of climate change: how potentials for acclimatization and

672 Therneau T.M. 2018. coxme: Mixed Effects Cox Models. R package version 2.2-10.

673 Timmerman C.M. and L.J. Chapman. 2004. Behavioral and physiological compensation for chronic 674 hypoxia in the sailfin molly (Poecilia latipinna). Physiol Biochem Zool 77:601-610.

675 Trompeter W.P. and T. Langkilde. 2011. Invader danger: Lizards faced with novel predators exhibit 676 an altered behavioral response to stress. Hormones and Behavior 60:152-158. 
677 Wingfield J.C., D.L. Maney, C.W. Breuner, J.D. Jacobs, S. Lynn, M. Ramenofsky, and R.D.

678 Richardson. 1998. Ecological bases of hormone-behavior interactions: the "Emergency

679 Life History Stage.” Am Zool 38:191-206.

680 Wong B.B.M. and U. Candolin. 2015. Behavioral responses to changing environments. Behav Ecol $681 \quad 26: 665-673$.

682 Woods H.A. and J.N. Smith. 2010. Universal model for water costs of gas exchange by animals and 683 plants. Proc Nat Acad Sci 107:8469-8474. 
Figures legends

685 Figure 1. Summarized chronology of the experiment across months.

686

687 Figure 2. Average change in body mass during the laboratory experiment $\left(\mathrm{A}, \Delta \mathrm{M}_{\mathrm{b}}\right.$ in grams \pm 688 SE) and change in body size growth during and after the laboratory experiment $(\mathbf{B}, \Delta \mathrm{SVL}$ in $\left.\mathrm{mm} \cdot \mathrm{d}^{-1} \pm \mathrm{SE}\right)$. Change was calculated since the beginning of the experiment. Control individuals are represented by a circle; water-restricted individuals are represented by a square. Symbols indicate the significance of the difference between treatments at each measurement: n.s. $=$ non-significant, $\dagger$ $\mathrm{p}<0.10, *=\mathrm{p}<0.05, * * \mathrm{p}<0.01, * * * \mathrm{p}<0.001$

Figure 3. Time spent before emergence (in 15 minutes steps) $(A, \pm S E)$ and proportion of time spent basking $(\mathrm{B}, \pm \mathrm{SE})$ by lizards in their home cages during morning (laboratory experiment). Symbols similar to those of Figure 2.

Figure 4. Mean exploration score $(A, \pm S E)$ calculated from behavioral measurements in a neutral arena at each session, and intra-individual change in thermal preferences since the beginning of the experiment $\left(\mathbf{B}, \Delta \mathrm{T}_{\mathrm{p}}\right.$ in $\left.{ }^{\circ} \mathrm{C}, \pm \mathrm{SE}\right)$. Black and grey symbols represent females and males, respectively. Other symbols similar to those of in Figure 2.

Figure 5. Intra-individual change in basal metabolic rate variation calculated from $\mathrm{O}_{2}$ consumption $\left(A, \triangle R M R\right.$ in $\left.m L \cdot h^{-1} \pm S E\right)$ and standard evaporative water loss rates $(\mathbf{B}, \Delta T E W L$ in $\mathrm{mg} \cdot \mathrm{h}^{-1} \pm \mathrm{SE}$ ) during and after the laboratory experiment. Change was calculated since the beginning of the experiment. In B, black and grey symbols represent females and males, 


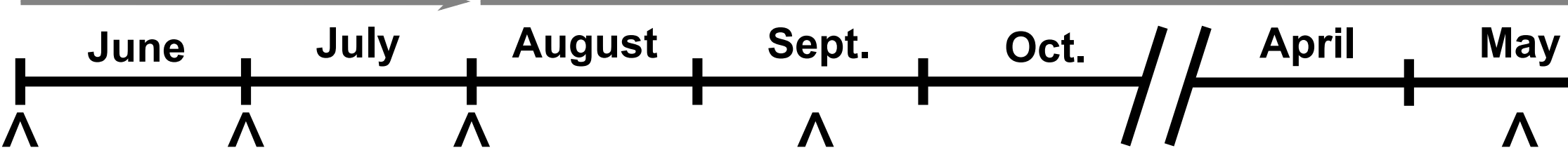

\section{Pre-restriction}

Week 0
Mid-restriction

Week 4
Post-restriction

Week 7
Hibernation
May 2017

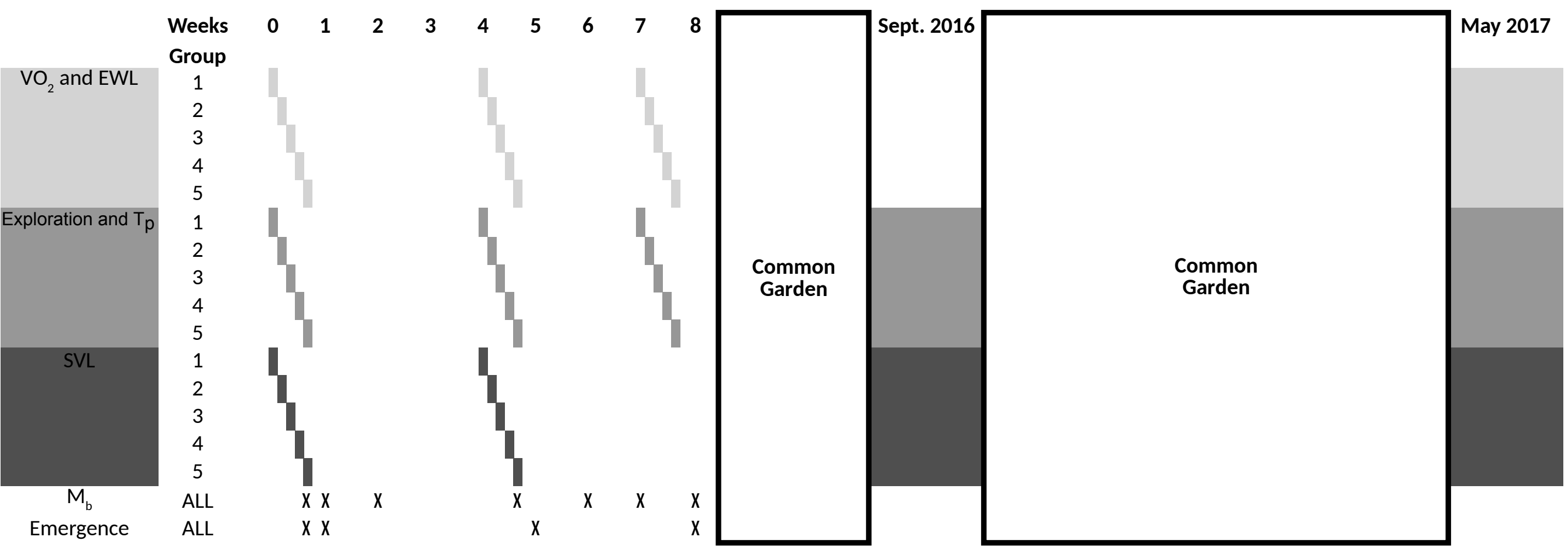




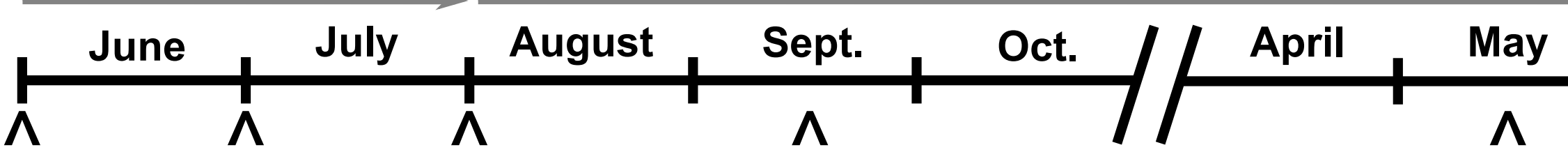

\section{Pre-restriction}

Week 0

\section{Mid-restriction}

Week 4
Sept. 2016

Week 7
Hibernation
May 2017
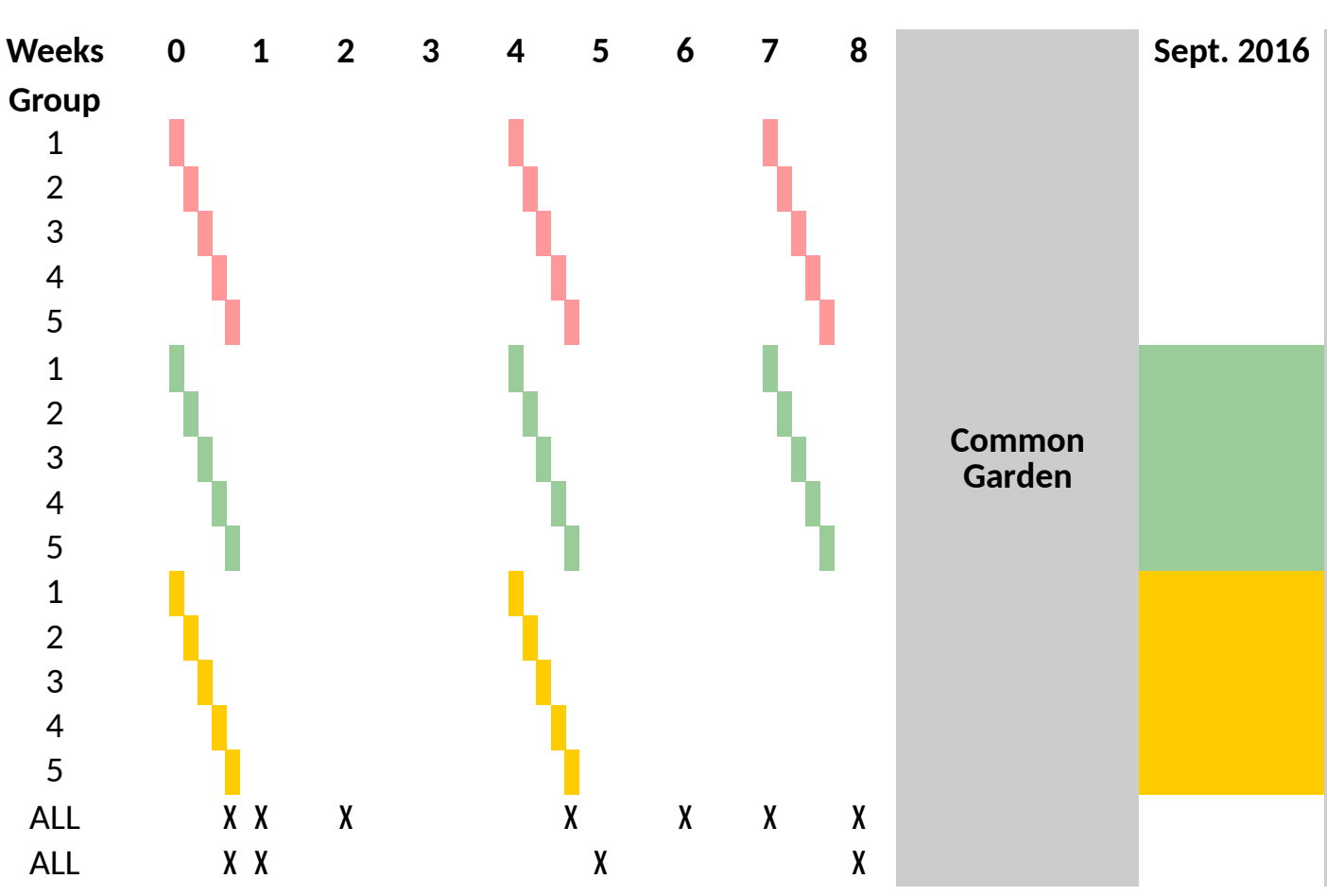

May 2017

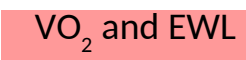

SVL

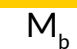

Emergence

ALL

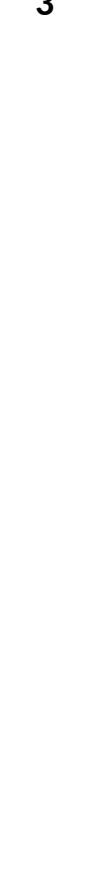



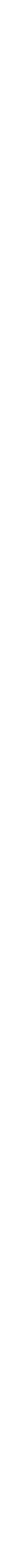

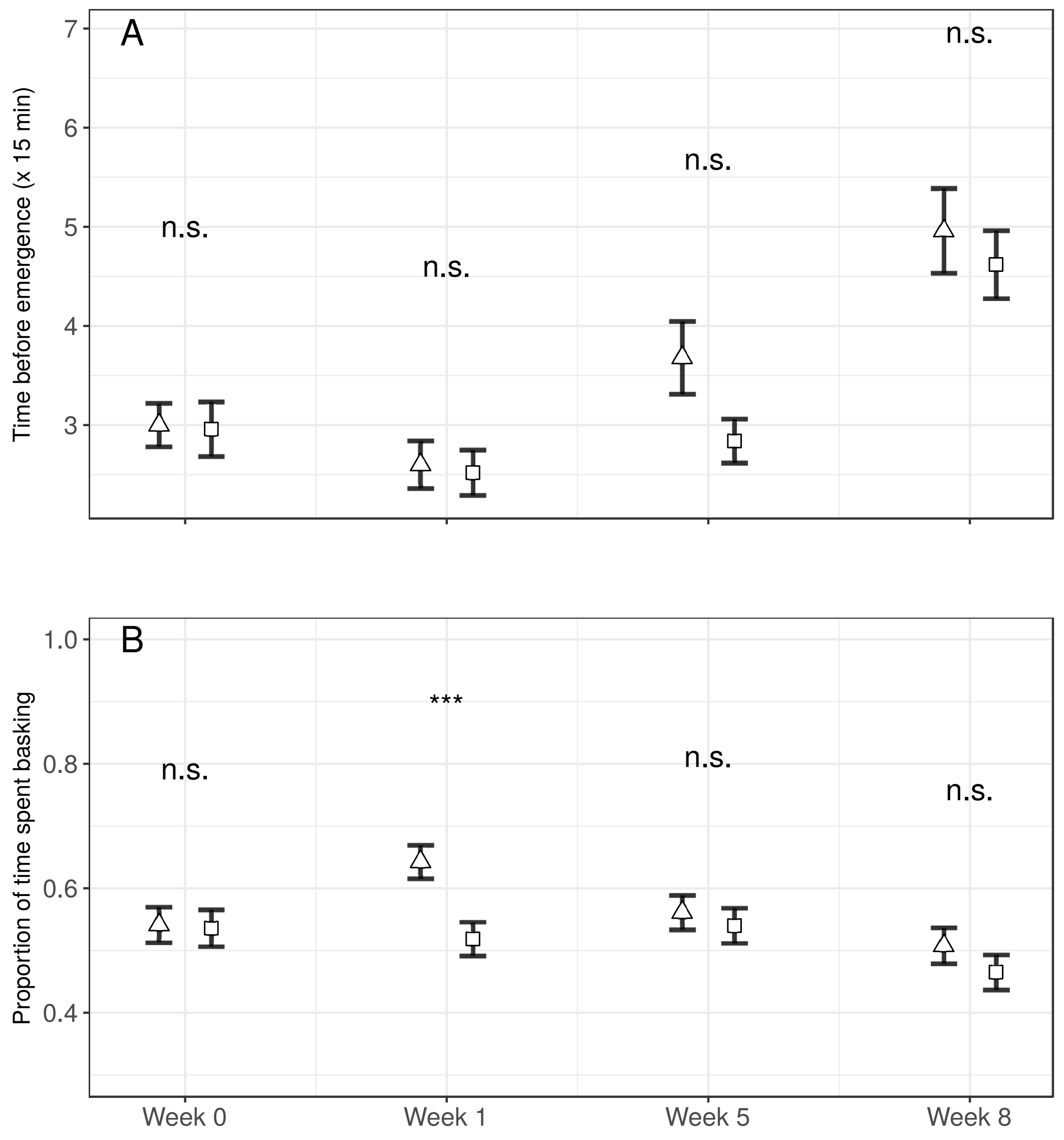

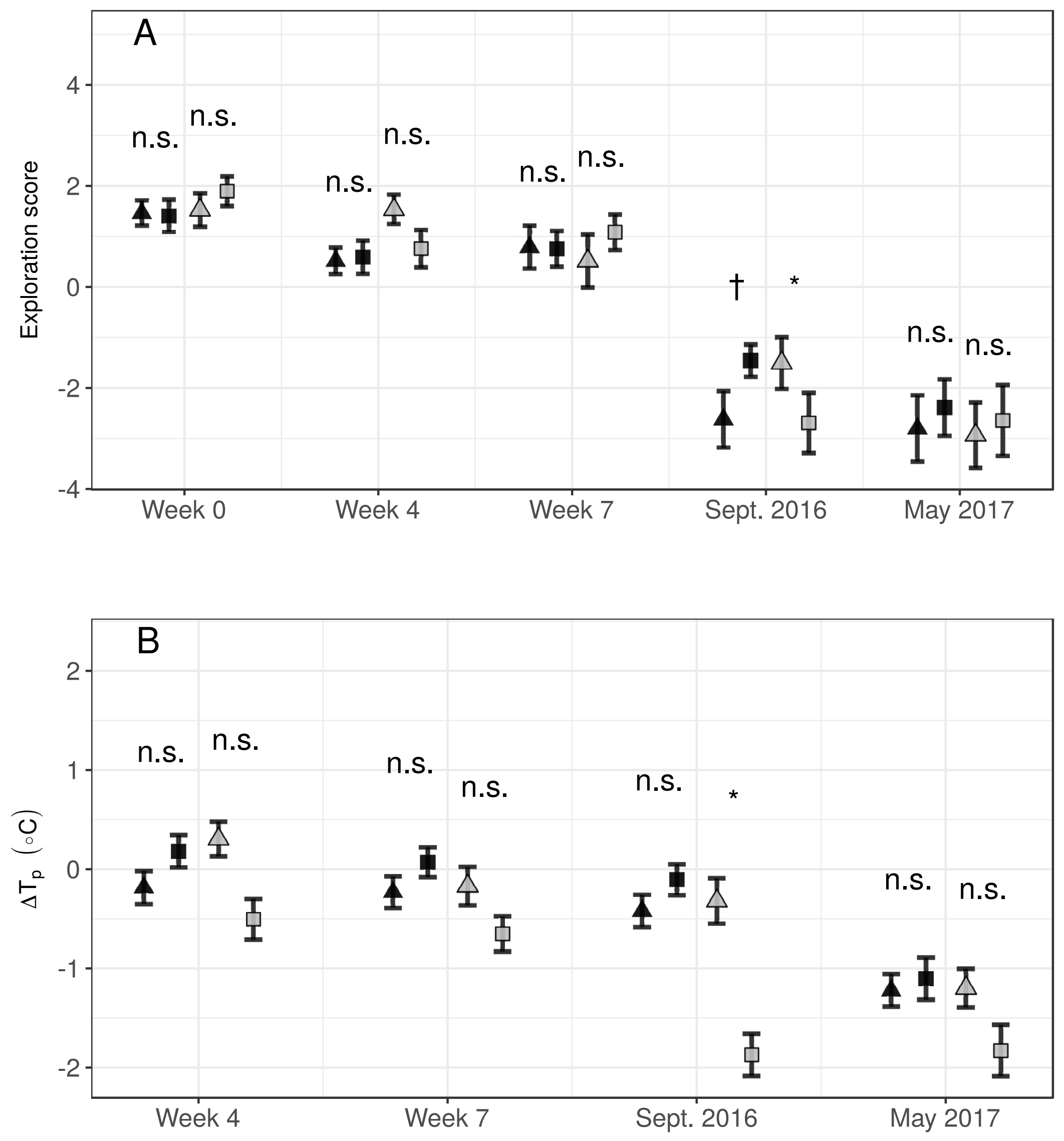

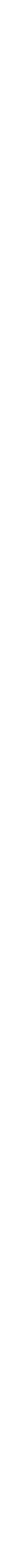
Table 1

\begin{tabular}{|c|c|c|c|c|}
\hline \multirow{2}{*}{} & \multicolumn{2}{|c|}{ Control individuals } & \multicolumn{2}{c|}{ Water restricted individuals } \\
\cline { 2 - 5 } & Females & Males & Females & Males \\
\hline $\mathrm{M}_{\mathrm{b}}(\mathrm{g})$ & $1.68 \pm 0.04$ & $1.57 \pm 0.04$ & $1.64 \pm 0.04$ & $1.57 \pm 0.03$ \\
\hline $\mathrm{SVL}(\mathrm{mm})$ & $49.6 \pm 0.4$ & $46.5 \pm 0.5$ & $50.0 \pm 0.5$ & $46.3 \pm 0.5$ \\
\hline $\mathrm{T}_{\mathrm{p}}\left({ }^{\circ} \mathrm{C}\right)$ & $33.4 \pm 0.1$ & $33.2 \pm 0.1$ & $32.9 \pm 0.1$ & $33.9 \pm 0.1$ \\
\hline $\mathrm{RMR}\left(\mathrm{mL} \cdot \mathrm{h}^{-1}\right)$ & $0.32 \pm 0.01$ & $0.30 \pm 0.01$ & $0.31 \pm 0.01$ & $0.32 \pm 0.01$ \\
\hline TEWL $\left(\mathrm{mg} . \mathrm{h}^{-1}\right)$ & $3.6 \pm 0.2$ & $4.0 \pm 0.2$ & $3.8 \pm 0.2$ & $4.2 \pm 0.3$ \\
\hline
\end{tabular}

Physiological and behavioral parameters measured at week 0 (before the start of the water restriction treatment). Values are average \pm standard error. See text for abbreviation definitions. 


\section{Appendix}

Appendix 1 and Table A1: Estimation methods of exploration rate following Rozen-Rechels et al. (2018).

Appendix 2: Effects of water restriction on survival from the end of the experiment to the next reproductive season.

Appendix 3: Effects of water restriction on reproductive effort of females during the next reproductive season.

Table A2: Model statistics of model explaining variation of $\triangle T E W L$ when adding $\triangle R M R$ as a fixed additive variable. 


\section{Appendix 1}

Behavioral statistics were measured from videos, transformed into image sequences, using the image analysis protocol of Rozen-Rechels et al. (2018). We measured the relative time spent active (T), the total distance walked by the lizard (D), the number of activity bouts (i.e., number of sequences of consecutive images with positive step length, $\mathrm{N}_{\text {bouts }}$ ), the average distance walked during a bout ( $\left.D_{\text {bouts }}\right)$, the average distance walked between two images in a bout $\left(\mathrm{M}_{\text {bouts }}\right)$, the mean standard deviation of distances walked between two images in a bout (homogeneity of displacements; $\left.\mathrm{SD}_{\text {bouts }}\right)$, the time spent by the lizard in the buffer zone along the walls $\left(\mathrm{T}_{\text {walls }}\right)$, the total distance walked out of the buffer zone ( $\left.D_{1 \text { walls }}\right)$, the mean distance to the walls $\left(\mathrm{D}_{2 \text { walls }}\right)$, and the standard deviation of the distance to the walls $\left(\mathrm{SD}_{\text {walls }}\right)$. We further subdivided the neutral arena into 24 equal squares, to estimate the total area visited by the lizards including the proportion of squares visited at least once by the individual ( $\left.\tau_{\text {explo }}\right)$ and the standard deviation of the number of locations per square or heterogeneity of the exploration $\left(\mathrm{SD}_{\text {explo}}\right)$.

In order to calculate the exploration rate, we transformed each behavioral trait using a Box-Cox power function to meet gaussian requirements. We used principal component analysis (PCA) (R package "ade4", Dray and Dufour 2007) to identify correlated behaviors (i.e. behavioral syndromes). The first component of the PCA (PC1) corresponded to the one identified by RozenRechels et al. (2018) as an exploration syndrome (same correlations between variables; see Table A1). PC1 scores, positively correlated to the time spent walking or the distance walked, were then extracted and individuals were ranked according to them. 
Table A1

\begin{tabular}{|c|c|c|}
\hline Behavioral measurements & Contribution to PC1 & Contribution to PC2 \\
\hline $\mathrm{D}$ & 0.14 & 0.002 \\
\hline $\mathrm{T}$ & 0.12 & 0.0001 \\
\hline $\mathrm{N}_{\text {bouts }}$ & 0.06 & 0.003 \\
\hline $\mathbf{M}_{\text {bouts }}$ & 0.13 & 0.003 \\
\hline SD bouts & 0.12 & 0.0001 \\
\hline Dbouts & 0.12 & 0.00009 \\
\hline $\mathrm{T}_{\text {walls }}$ & 0.02 & 0.24 \\
\hline $\mathrm{D}_{1 \text { walls }}$ & 0.14 & 0.015 \\
\hline $\mathrm{D}_{2 \text { walls }}$ & 0.02 & 0.27 \\
\hline $\mathrm{SD}_{\text {walls }}$ & 0.0001 & 0.31 \\
\hline$\tau_{\text {explo }}$ & 0.06 & 0.11 \\
\hline $\mathrm{SD}_{\text {explo }}$ & 0.07 & 0.05 \\
\hline
\end{tabular}

Contributions of each measured behaviors to the axes of the PCA. Bold contributions are those higher than a random contribution (i.e. 100/12=8.33\%). Axis 1 explained 55\% and axis 2 explained $23 \%$ of of the variance in the data. 


\section{Appendix 2}

We estimated survival from recapture data collected in May 2017. It was then possible to estimate lizard survival with a high degree of reliability thanks to a recapture probability close to 1 . Recapture effort in September 2016 was not high enough to ensure sufficient confidence in the survival data. Still, we recaptured individuals from the experiment in May 2018 that have not been captured in 2017 (3 individuals). We then analyzed survival from August 2016 to May 2017 considering they were alive even though not captured. We excluded individuals that have been paralyzed due to decalcification at the end of July.

Survival has been analyzed using a mixed-effect logistic regression model including a logit link and a binomial error term (package lme4) with a two-way interaction of the water restriction treatment with the sex of the individual as fixed effect and the enclosure identity as a random effect. Treatment had not significant effect on survival, whatever the sex (treatment $\times \operatorname{sex}: \chi^{2}=2.1, \mathrm{df}=1$, $\mathrm{p}=0.15$; treatment: $\chi^{2}=0.07, \mathrm{df}=1, \mathrm{p}=0.79$ ). Males had a significantly higher survival than females $\left(\chi^{2}=4.77, \mathrm{df}=1, \mathrm{p}=0.03\right)$. 


\section{Appendix 3}

We estimated the reproductive effort of females recaptured in May 2017 by calculating total litter size and mass (i.e. the number and summed mass of all not-fecundated eggs, aborted embryos, dead juveniles and live juveniles in the litter) and calculating litter size and mass (i.e. only in live juveniles). One female was not pregnant and has been excluded from the analysis.

(Total) litter size was analyzed using a mixed-effect logistic regression model including a logit link and a Poisson error term (package lme4, Bates et al. 2015) with the water restriction treatment as fixed effect and the enclosure identity as a random effect. (Total) litter mass was analyzed using a mixed-effect linear model (package nlme) with the water restriction treatment as fixed effect and the enclosure identity as a random effect.

Neither (total) litter size nor mass were affected by the water restriction treatment (all $p>0.19$ ). 
Table A2

\begin{tabular}{|c|c|c|c|c|c|}
\hline \multirow{3}{*}{ Sessions } & Variable & $\begin{array}{c}\text { Numerator } \\
\text { DDL }\end{array}$ & Denominator & DDL & $\boldsymbol{P}$ \\
\hline \multirow{5}{*}{ Weeks 4 and 7 } & $\Delta$ RMR & 1 & 95 & 3.38 & 0.06 \\
\cline { 2 - 6 } & Time & 1 & 95 & 22.3 & $<0.0001$ \\
\cline { 2 - 6 } & Treatment & 1 & 97 & 1.11 & 0.30 \\
\cline { 2 - 6 } & Time $\times$ Treatment & 1 & 95 & 0.61 & 0.44 \\
\hline \multirow{3}{*}{ May 2017 } & $\Delta$ RMR & 1 & 47 & 1.19 & 0.28 \\
\cline { 2 - 6 } & Sex $\times$ Treatment & 1 & 47 & 4.51 & 0.0 \\
\hline
\end{tabular}

Effect of the water restriction treatment on $\triangle T E W L$ when adding $\triangle R M R$ as a fixed additive effect to the previously selected model. Results are unchanged (see Results section). 
Dear Mr. Rozen-Rechels:

An editorial decision has been made regarding your revised manuscript, "Acclimation to water restriction implies different paces for behavioral and physiological responses in a lizard species" (PBZ-19062R1).

I have read your paper and received reports from Reviewers 2 and 3, in addition to input by the Handling Editor for your paper, who is a member of the PBZ Editorial Team. The reviewers returned constructive comments, though their recommendations are mixed, with some additional changes requested. We believe that the manuscript could make a good contribution to the field if appropriate final changes are made.

The reports below present you with comments ranging from minor editorial corrections to more substantive concerns, which will need to be fully addressed before a final editorial decision can be made. We would like to provide you with the opportunity to address these remaining remarks in a final revision. Therefore, we are inviting you to revise and resubmit the paper within 30 days. Please contact us if you will need more time.

The reviewers' comments are below. As you revise your paper, please pay careful attention to this input, responding to each remark in detail, and noting what changes you made to the paper in the response. Your detailed responses to reviewers and list of changes to the paper will be very helpful during the final editorial evaluation of your paper.

If you have additional information that you would like to have published with your paper, please consider submitting it as appendices or online supplements.

When your revision is complete, please submit it online at www.editorialmanager.com $/ \mathrm{pbz}$, uploading each figure and table separately, with figures as high-resolution image files (300 or more dpi) and tables as editable documents.

Thank you again for considering PBZ as an outlet for your work. We will be looking forward to reading your revised paper.

Sincerely,

Theodore Garland, Jr.

Editor in Chief

Physiological and Biochemical Zoology

Response: First, we would like to thank the journal, its editorial board and the reviewers who all helped significantly improving our manuscript. We thank Pr. Theodore Garland, Jr. for considering our manuscript for publication. We answered the editor and the reviewer concerns point-by-point below and revised the main text accordingly.

\section{Editorial Comments}

Thank you for your diligent revisions, which have improved the paper. In addition to the very helpful input from the referees, there are a few editorial recommendations that we would like you to take into consideration as you make final changes to the manuscript. 
Response: We thank the associate editor for supporting our paper for publication. We took the recommendation of the editor and the referees in account and responded to it point-bypoint. We also updated our acknowledgements to thank the editor and the referees for significantly improving our manuscript.

Changes are highlighted in color in the new version of the manuscript.

First, please outline for readers, within the body of the paper, the same clarifications that you offer to the referees. Our reviewers are representative of the readers of PBZ, and their concerns will likely be shared.

Response: As detailed in our point-by-point response, we updated the text where Reviewer 2 asked to.

Second, please update Figure 1 by providing a grayscale version for potential print publication. The color image can be retained for potential publication in the online version.

Response: We provided two versions of figure 1, a coloured one and a grayscale one.

Third, please consider citing the attached paper, if relevant:

Kelly, S. A., T. M. Panhuis, and A. M. Stoehr. 2012. Phenotypic plasticity: molecular mechanisms and adaptive significance. Comprehensive Physiology 2:1417â€"1439.

Response: We thank the associate editor for suggesting this reference. We have decided to cite this paper when introducing adaptive plasticity (line 42) and discussing beneficial acclimation (line 390). See lines 584-585 in the reference list.

Reviewer 2 Comments

The authors have made a good attempt to address the original review comments, and I thank them for their effort. I have a few small items that are still outstanding.

Response: We thank the reviewer for validating the changes we have made which significantly improved our manuscript.

The reference by Kennett and Christian has been removed from the text but still appears in the reference list at the end.

Response: The reference had been deleted from the list.

My comment about adequately taking body size into account may have not been clear. I was not suggesting that some other metric other than mass should have been used - I absolutely agree that mass is the appropriate metric to use. My comment was related to clarification about how the body size (mass) was taken into account statistically. In the Response to Reviewers document, the authors state: "We used body mass instead of body size in our ANCOVA as it ..." So, if ANCOVA was used, then that satisfies my concern. However, when I refer back to the text, there is still no reference to the term "ANCOVA". The authors mention that mass was used in the model, but that is not sufficient for me to understand how it was incorporated in the model. If appropriate, please include the term "ANCOVA" in the text, and this will satisfy my concern. If, on the other hand, ANCOVA 
was not used, then further explanation is required to convince a reader like me that body mass was appropriately

included in the statistical comparisons.

Response: An ANCOVA was used and in the case of studying RMR and TEWL variations, body mass scaling was taken into account by adding the body mass as a fixed effect. We changed the text accordingly (line 274: "trait variation was analyzed with ANCOVAs using linear models" and line 278 "For $\triangle R M R$ and $\triangle T E W L$, we included individual $M_{b}$ as a fixed effect in the ANCOVA to account for body mass scaling.").

Similarly, in the Response to Reviewers document, the authors have adequately addressed my concerns about the way the IR thermometer was used. However, that is not reflected in the text. The text makes reference to the $6 \mathrm{~mm}$ diameter spot, but there is no mention of the lasers that the thermometer provides. By mentioning the lasers in the text, you will convince readers like me that you were able to direct the beam onto lizards skin rather than simply pointing it in the general direction of the lizard but measuring some part lizard skin and some part surrounding substrate. So, the authors just need to make the text as convincing as they have made the Response to Reviewers.

Response: As suggested by the reviewer we have also updated the manuscript to answer this concern (line 236-237: ", that we were able to assess thanks to three lasers indicating the centre of the circle and the diameter of the spot when measuring the temperature").

\section{Reviewer 3 Comments}

The authors have addressed all my comments and questions. It is a very well designed study with interesting results.

Response: We thank the reviewer for the positive support. 